\title{
Périgueux - Place de la Clautre
}

$n^{\circ} 026029$

\section{Philippe Calmettes}

\section{(2) OpenEdition \\ 1 Journals}

\section{Édition électronique}

URL : http://journals.openedition.org/adlfi/16429

ISSN : 2114-0502

Éditeur

Ministère de la Culture

Référence électronique

Philippe Calmettes, «Périgueux - Place de la Clautre », ADLFI. Archéologie de la France - Informations

[En ligne], Aquitaine, mis en ligne le 10 février 2016, consulté le 14 novembre 2019. URL : http:// journals.openedition.org/adlfi/16429

Ce document a été généré automatiquement le 14 novembre 2019.

(c) Ministère de la Culture et de la Communication, CNRS 


\title{
Périgueux - Place de la Clautre
}

\author{
$n^{\circ} 026029$
}

\section{Philippe Calmettes}

Lien Atlas (MCC) :

http://atlas.patrimoines.culture.fr/atlas/trunk/index.php?

ap_theme=DOM_2.01.02\&ap_bbox=-0.674;45.174;0.747;45.214

1 Un diagnostic archéologique réalisé au sommet du Puy Saint-Front, sur la place de la Clautre, a confirmé l'existence d'une occupation antique sous le vaste ensemble funéraire médiéval se développant au pied de la cathédrale actuelle (cf. fig.).

2 L'occupation antique est marquée par la présence d'un mur maçonné (larg. 0,60 m, haut. $0,90 \mathrm{~m}$ ) qui apparaît à $-1,60 \mathrm{~m}$ du niveau de circulation actuel de la place. Orienté nord-est-sud-ouest, il est couvent d'un enduit contre son parement oriental. Un lambeau de sol conservé contre son parement occidental permet de supposer qu'il peut s'inscrire dans une construction plus importante.

3 La nature des matériaux utilisés et la mise en œuvre employée sont caractéristiques de la fin de l'Antiquité. Cette construction, dont la nature et la fonction restent indéterminées, laisse place dès l'Antiquité tardive à des inhumations en sarcophage. Ces dernières sont directement installées contre le mur du bâtiment abandonné (cf. fig. 1).

4 L'intégration de cette construction dans l'organisation et la gestion de l'aire sépulcrale tardo-antique n'est pas improbable.

5 Au cours du Haut Moyen Âge ( $\mathrm{v}^{\mathrm{e}}-\mathrm{x}^{\mathrm{e}} \mathrm{s}$.), le bâtiment antique et les inhumations en sarcophage font place à une occupation plus «lâche », caractérisée par une succession de niveaux de circulations. Entre le $\mathrm{x}^{\mathrm{e}}$ et le $\mathrm{xII}^{\mathrm{e}} \mathrm{s}$., l'occupation se densifie avec l'élaboration d'une véritable voirie, puis d'un nouvel ensemble de tombes en sarcophage. Dans un laps de temps court, de nouveaux aménagements de voirie ou de place, pouvant être juste antérieurs, voire contemporains de la construction du monastère Saint-Front, oblitèrent cet état. Des inhumations se succèderont alors sans 
discontinuité tout au long du Moyen Âge sur plusieurs niveaux, s'inscrivant pleinement dans le cimetière qui entoure désormais l'église.

6 L'interaction entre ces différents espaces, bien que supposée - bâtiment antique, aire sépulcrale antique tardive, place et voirie médiévales ou encore cimetière paroissial -, n'avait auparavant pas été mise en évidence.
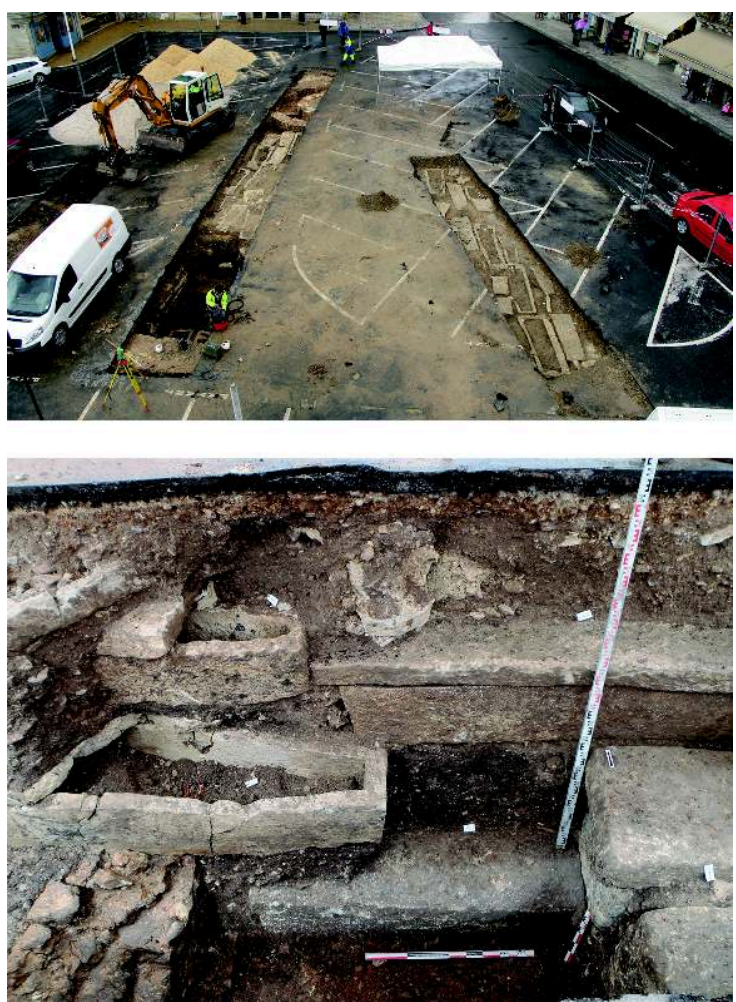

Fig. 1

Vue vers l'ouest, depuis la cathédrale Saint-Front, des deux tranchées réalisées au cours du diagnostic archéologique d'avril 2012.

Fig. 2

Au fond du sondage, installée sur la terrasse, la première inhumation en sarcophage mise en place après l'abandon du bâtiment antique (antiquité tardive).

\section{INDEX}

operation Opération préventive de diagnostic (OPD)

Index chronologique : Gallo-romain, Bas-Empire, Moyen Âge, Temps Modernes

Mots-clés : bâtiment, espace funéraire, sarcophage, voirie, cimetière

Index géographique : Aquitaine, Dordogne (24), Périgueux 
AUTEURS

PHILIPPE CALMETTES

Inrap 